\title{
K VPRAŠANJU TONALNOSTI IN VERTIKALE V SKLADBAH SLAVKA OSTERCA
}

\author{
Andrej Rijavec (Ljubljana)
}

Pri analizi klasične in deloma tudi baročne ter romantične glasbe $\mathrm{v}$. vseh njenih poznih in zapoznelih oblikah, je nauk o harmoniji, se pravi, nauk o funkcionalni povezanosti in odvisnosti akordov, podlaga, $s$ pomočjo katere se lahko razložijo sozvočja. Funkcionalna harmonija pa je samo eden izmed principov Osterčeve kompozicijske tehnike. Zato lahko z njo razložimo samo nekatere odseke skladateljeve glasbe.

Ker je tradicionalna harmonija pri Ostercu izgubila vodilno vlogo, je razumljivo, da je to dejstvo vplivalo na tonalnost njegove glasbe. Tako so tonalni stavki oziroma tonalne kompozicije redke. Vezane so predvsem na začetno skladateljevo razvojno fazo. Stavke, ki jih je uvrstiti $v$ tradicionalne tonalitete, najdemo tudi kasneje, pa čeprav so poslej količinsko izjemni. Tako je možno - v okviru komornega opusa - govoriti o F-duru v II. stavku (Passacaglia) I. godalnega kvarteta, enako v valčku Suite za 8 instrumentov, ali o D-duru v IV. stavku Suite za violino in klavir. Tudi po praškem študiju so Osterčeve skladbe - od Tria za violino, violo in violončelo in II. godalnega kvarteta - v glavnem zasnovane v določenih »tonalitetah«. Pri tem ne gre za skladbe oziroma stavke, pri katerih je tonalitet več, tako da $\mathrm{v}$ tradicionalnem pomenu besede izkazujejo določeno dispozicijo tonalitet, kot na primer III. in IV. ter zlasti I. stavek Divertimenta za kvartet na lok. Gre za stavke in skladbe, kjer občutek tonalnosti ne sloni na funkcionalnih zvezah med sozvočji, ampak nastane s poudarjanjem in izstopanjem določenega tona, ki ga je treba imeti za »tonalno" težišče kompozicije. Takih stavkov je cela vrsta: od Allegra appasionata I. godalnega kvarteta ${ }^{1}$ do Strette-Presta Kvinteta $\mathrm{za}$ pihala se vrstijo stavki, ki vsebujejo »tonalni« center $\mathrm{v}$ omenjenem smislu. To seveda ne pomeni, da Osterc v Ouverture Concerta pour violon, alto, violoncelle et piano, $\mathrm{ki}$ je »in $\mathrm{D}$ «, ne bi smel na koncu zaobrniti glasbeni tok v čisti D-dur; ali, na primer, da si v Sonati za violo in klavir ne bi smel dovoliti občasnega razširjevanja obravnavane »tonalnosti« $v$ smislu tradicionalne durovske oziroma molovske tonalitete. Kot povsod je tudi na tem

1 Prim. Rijavec A., Prvi i drugi gudački kvartet Slavka Osterca, Arti musices, Zagreb 1969, 178. 
področju za Osterca značilno povezovanje različnih principov; povezovanje tradicionalnega $\mathrm{z}$ novim, novega $\mathrm{s}$ tradicionalnim, sinteza pričakovanega $\mathrm{z}$ nepričakovanim.

Že na podlagi posameznih horizontalnih linij je možno marsikaj razbrati, kar prispeva $\mathrm{k}$ vprašanju tonalnosti. Ne more biti nobenega dvoma, da je na primer tema, ki jo $\mathrm{v}$ godalnem kvartetu iz leta 1923 prinese viola, v a-molu, pa čeprav se giblje $\mathrm{v}$ njegovi harmonski kakor tudi naravni varianti. $\mathrm{V}$ tem primeru je realizacija celotne zvočnosti vpeta $\mathrm{v}$ tradicionalno harmonijo, tako da je tema $\mathrm{v}$ »premem sorazmerju $s$ tonalnostjo kompozicije. Podobno se dogaja tudi po Pragi - v Passacaille Concerta ali v Larghettu Suite za violino in klavir, pa čeprav $\mathrm{v}$ teh in takih primerih harmonsko tuji toni nasičujejo vertikalo, ne da bi mogli popolnoma zamegliti tonalitete, ki jo izpričuje celota, kaj šele posamezne instrumentalne linije. Kakor je tema v Fugi

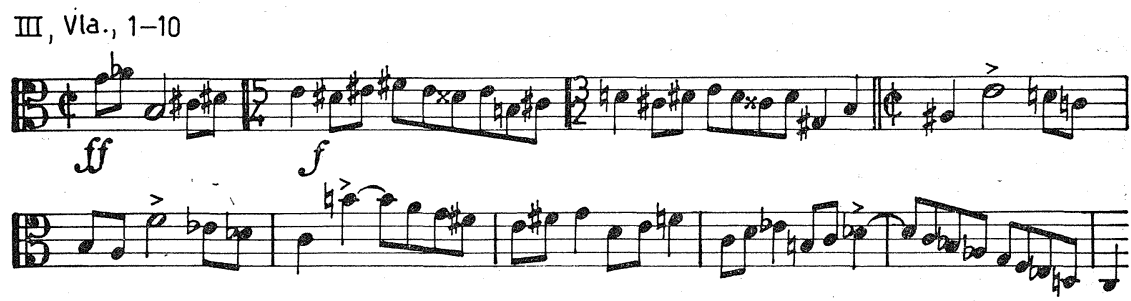

I. godalnega kvarteta $\mathrm{v}$ svoji glavi in $\mathrm{v}$ zaključku $\mathrm{v}$ c-molu in kakor lahko $\mathrm{v}$ njenem poteku zavoljo stalnega moduliranja določimo več tonalnih središč, tako se ta tonalna neutrjenost pojavlja tudi pri ugotavljanju osnovne tonalitete stavka. Možno jo je kvečjemu fiksirati na $\mathrm{C}$ kot osrednjem tonu. Vendar Osterc tudi temu noče dati popolne prednosti ter s poudarjanjem dominante in vodilnega tona utrdi $\mathrm{v}$ zaključku skladbe popolnoma drugo tonaliteto D-dur. Odmik od tradicionalnega se kaže tudi v tem, 'da temo I. stavka istega kvarteta - razen dveh kromatičnih prehajalnih tonov - oblikuje izrazito celotonsko; ${ }^{2}$ ali, kot na primer v II. stavku (Andante) Sonatine za dva klarineta, da v spevni melodiji, ki je razen dveh bežnih kromatičnih izmikov in enkratnega nastopa vodilnega tona grajena diatonsko (Des-dur), hkrati poudari implicitno pentatoniko. Ker mu slednja rabi kot vedno znova ponavljajoča se ostinatna podlaga, se s tem ruši durovska kvaliteta osnovne linije in stavka, zato pa izstopa njuno skupno težišče na Des.

Presenetljiva, a vendar točna je trditev, da se Osterc v svojem skladanju ni nikoli popolnoma odpovedal tradicionalnim funkcionalnim harmonskim odnosom; ne sicer $\mathrm{v}$ vsej njihovi celovitosti, vsekakor pa $\mathrm{v}$ njihovi najbolj tipični obliki, $\mathrm{v}$ odnosu dominanta-tonika; če že ne istočasno $\mathrm{v}$ celotnem sozvočju, pa $\mathrm{v}$ unisono vseh oziroma vsaj v postopih posameznih instrumentalnih glasov. Celo v atonalnih kompozicijah, izjemi sta zopet Trio za violino, violo in violončelo ter II. godalni kvartet iz leta 1934, vpleta v nekatere stavke harmonske zveze, ki bodi $\mathrm{v}$ posameznih prebliskih bodi $\mathrm{v}$ še tehtnejših zaključkih vnašajo $\mathrm{v}$ atonalno fakturo tonalne elemente. In to ne samo takrat, ko

2 Ib., 179. 
ironizira preteklost, ampak tudi tedaj, ko resno in $\mathrm{v}$ smislu disonantnejših zvočnih naziranj oblikuje glasbeno tkivo.

Da je najti tradicionalno kadenciranje pred njegovim študijem v Pragi, je povsem razumljivo; to je $\mathrm{v}$ času, ko so njegove partiture tudi polne varljivih kadenc in šolskega, harmonsko izrazitega sekvenciranja, ki najde svoj zapozneli odmev celo v Allegru Kvinteta za pihala. Dominantno-tonične odnose pa je možno zasledovati tako $\mathrm{v}$ njegovem praškem diplomskem delu, I. godalnem kvartetu, kot tudi poslej. Tako v Passacaglii tega kvarteta skoraj vse nastope ostinatne linije zaključuje $\mathrm{z}$ vrnitvijo $\mathrm{v}$ dominantno območje. Enako v Passacaille Concerta, medtem ko za zvezo dominanta-tonika v Chaconne Partite za violončelo in klavir skrbi samo ostinato $\mathrm{v}$ basu, ki

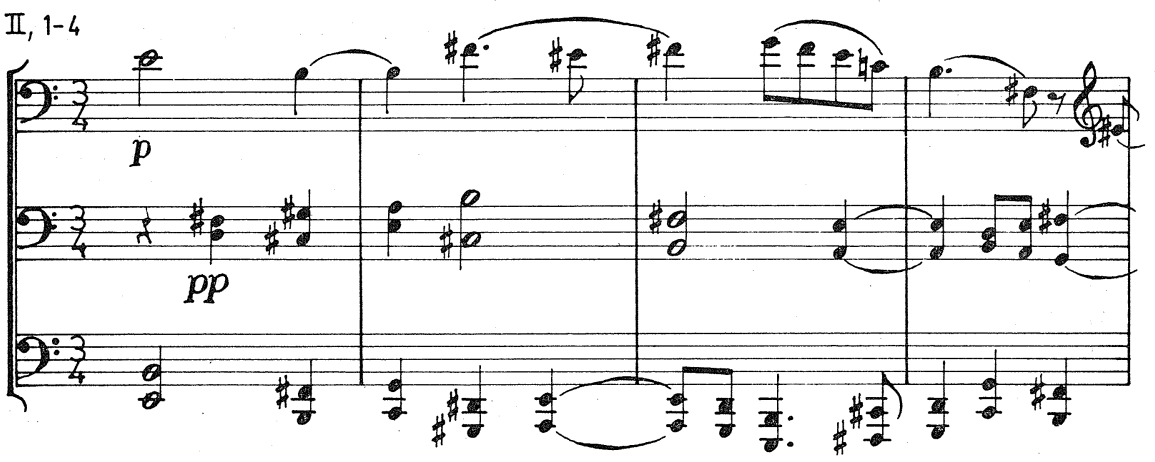

povrhu še niha med E-durom in e-molom. Seveda take harmonske zveze vključuje tudi $\mathrm{v}$ stavke, ki izpričujejo samo osrednji ton, ki pa ga skladatelj ob koncu še kadenčno utrdi. ${ }^{3}$ Bolj nenavadno pa je, da je take in podobne primere zaslediti $\mathrm{v}$ atonalno koncipiranih kompozicijah, kot sta na primer Trio pour violon, violoncelle et piano ${ }^{4}$ in Sonate pour violoncelle et piano. ${ }^{5}$

Tako kot tradicionalno kadenciranje najde tudi kromatično moduliranje svoj odmev $\mathrm{v}$ delih, ki nastanejo v skladateljevi zreli ustvarjalni epohi. Tak je prehod iz Larga $v$ Scherzando Sonate pour violoncelle et piano:

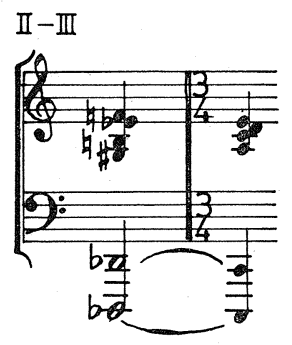

3 Prim. npr. V. stavek Suite za 8 instrumentov.

4 Prehod $\mathrm{v}$ zaključni Choral in konec, kar pa na tem mestu podpira izrazito kvintna zasnovanost basovskega parta klavirja in violončela.

5 I, 50-51; IV, 35-36; V, 140-142. 
Če je v tej modulaciji dodana samo ena sekunda, pa je le-teh v zaključni gradaciji I. stavka Noneta več. Izsek, ki pravzaprav predstavlja kromatično sekvenco, je $\mathrm{v}$ dominantnih pozicijah kljub dodanim oziroma alteriranim tonom funkcionalno sprejemljiv. Prehodne tonike so seveda »tonične« samo $\mathrm{v}$ diskantu. Tako tudi ta primer ilustrira povezovanje podedovanih principov $\mathrm{z}$ novimi estetskimi zahtevami zaostrovanja vertikale.

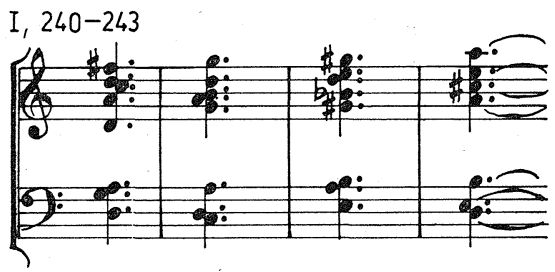

Kot posebno zanimivo mesto kaže omeniti pasus $\mathrm{v}$ smislu sentimentalne, salonske romantične glasbe, ki ga je Osterc vpletel v Andante Tria pour violon, violoncelle et piano. Medtem ko klavir spremlja $v$ razloženih postopih,
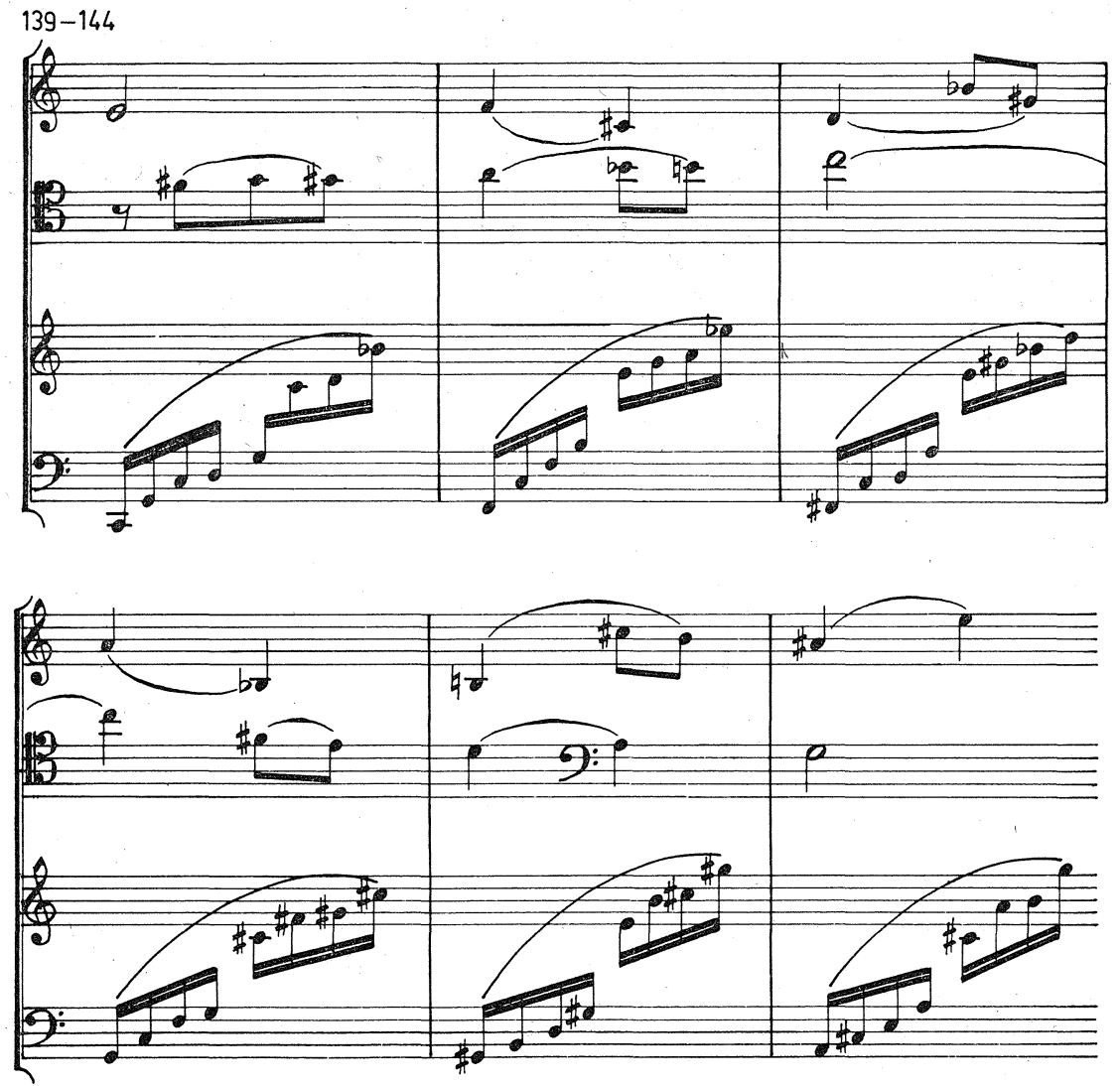
violina pa $\mathrm{v}$ presenetljivem, na prvi pogled kar atonalno zasnovanem kontrapunktu, začne violončelo $\mathrm{s}$ svojo, $\mathrm{v}$ začetku močno kromatizirano, spevno linijo, ki jo v 143. taktu prevzame violina. Kromatične modulacije, v katerih se vodilni toni vedno ne razvezujejo, ampak zavoljo spreminjajoče se harmonije prevzemajo vedno nove funkcije, vsekakor slone na terčnih harmonijah bolj ali manj popolnih ter alteriranih tri-, četvero- in peterozvokov. Zategadelj in zaradi nekaterih prehajalnih oziroma dodanih izvenharmonskih tonov nastajajo trdote, ki jih salonski stavek sicer ne bi imel. Ravno te občasne disonance vodijo $\mathrm{k}$ hipotezi, da gre za norčevanje iz sentimentalnosti, ki je Oster nikakor ni prenašal. Njegova čustvenost je pač veliko bolj napeta in ekspresivna, da bi v resnici prebavila tako plitkost. Da je temu res tako in da gre verjetno res samo za satiro, potrdi ponovna vrnitev $\mathrm{v}$ atonalno fakturo.

Tako se Oster svobodno giblje med tonalnim in atonalnim. Vendar je le redko popolnoma dosleden $\mathrm{v}$ okviru enega ali drugega. Že nekatere njegove teme so pokazale, kako niha celo med durom in molom. Razumljivo, da se podobna hotenja razkrivajo tudi $\mathrm{v}$ vertikali, $\mathrm{v}$ sozvočjih, $\mathrm{v}$ katerih istočasno projicira obe po tradiciji nasprotujoči si tonaliteti. ${ }^{6}$ Manjša strogost $\mathrm{v}$ obravnavajanju klasičnih dur-molovskih principov pa pride na površje že $\mathrm{v}$ prvih komornih delih tudi $\mathrm{v}$ enharmonsko zapisanih sozvočjih, ki razkrivajo hotenje, da se vsaj $\mathrm{z}$ notnim zapisom razrahlja tradicionalna funkcionalnost akordov. ${ }^{7}$

Odnos do zvoka se je Ostercu močno spremenil s študijem v Pragi, zlasti pod vplivom avantgardnih nazorov dveh profesorjev - Aloisa Hábe in Karla Boleslava Jiráka. Praško bivanje mu je odprlo vrata $\mathrm{k}$ novim, njemu še neizhojenim potem, ne da bi vplivalo tudi razdiralno, namreč, da bi skladatelj zavrgel vse, iz česar je izšel. Znano je, da je leta 1930 zapisal, »da tradicija ni ovira pri ustvarjanju novih vrednot, ampak pripomoček.$^{8} \mathrm{Na}$ področju oblikovanja zvoka se je to kazalo tako, da je včasih tudi v starih okvirih skušal zadostiti svojim zvočnim iskanjem, in sicer s povezovanjem dveh tonalitet. Dober primer bitonalnosti nudi Valse v njegovih Silhuetah za godalni kvartet.

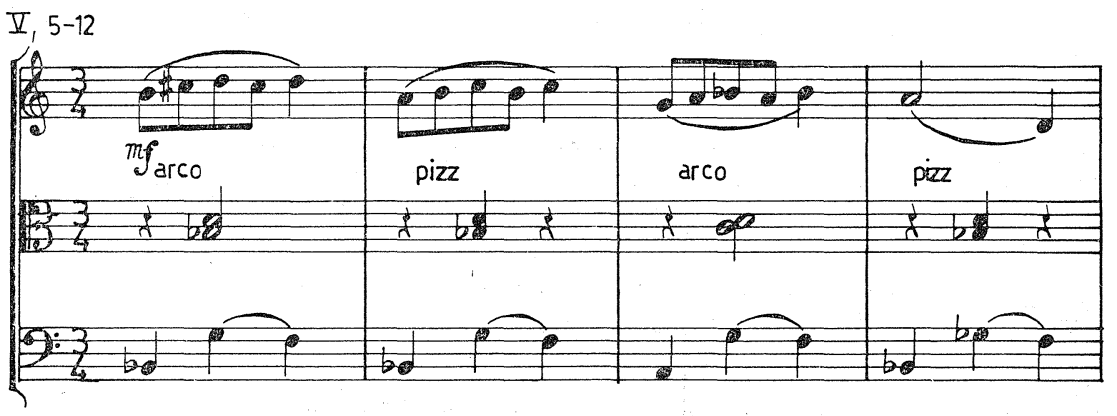

${ }_{6}^{6}$ Prim. Koncert za violino in 7 instrumentov, 239, ali Kvintet za pihala, I, 21.

7 Rijavec A., Komorno kompozicijsko snovanje Slavka Osterca pred njegovim odhodom v Prago, MZ V, Ljubljana 1969, 93-94.

${ }^{8}$ Bedina K., Nazori Slavka Osterca o tradiciji v glasbi in o glasbenem nacionalizmu, MZ III, Ljubljana 1967, 90. 
Opreka je vidna zlasti $\mathrm{v}$ 23. taktu, $\mathrm{v}$ katerem trije gornji instrumentalni glasovi dominantno kadencirajo, spodnji pa tudi, a drugam:

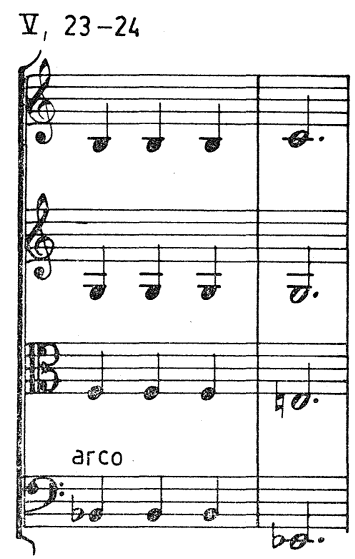

Glavna posledica praškega študija je bila gotovo atonalnost, ki je Slavka Osterca $\mathrm{v}$ različnih razmerjih in sintezah $\mathrm{z}$ nasprotnim, tonalnim polom spremljala do njegove smrti - od štirih karikatur za pikolo, klarinet in fagot do Sonate pour violoncelle et piano. Pri tem je značilno, da pomeni leto 1934 višek nakopičenja disonantnega zvoka, saj ni disonantnost ne poprej ne poslej tako kljubujoča in izsiljujoča. Tako so do Tria in Kvarteta (1934) samo nekateri stavki atonalno koncipirani: Preludij in Kanon v Silhuetah, srednji del Passacaille iz Sonate za violo in klavir, ali na primer osrednji del Fantazije za violino in klavir. Iz tega obdobja je poučen in zanimiv Menuetto iz Concerta pour violon, alto, violoncelle et piano, ker dovoljuje razširitev atonalnih razsežnosti $\mathrm{v}$ nekaj, kar bi lahko imenovali poliatonalnost. S kanoničnim sosledjem štirih oziroma petih atonalno koncipiranih linij skladatelj namreč naklada več atonalnih zvočnih plasti. (Prim. faks. na str. 44.)

Po II. godalnem kvartetu ostane atonalnost $\mathrm{v}$ ospredju, a se tudi vanjo vnašajo tonalni elementi. Osterc si dovoli celo tonalno fakturo, kot na primer $\mathrm{v}$ prej omenjenemu satiričnemu vstavku iz Tria pour violon, violoncelle et piano, ali pa zavoljo predloge popolnoma tradicionalizira kompozicijski stavek. Tako vrnitev $\mathrm{v}$ lastne tradicionalnejše vode predstavljajo Variacije na slovensko narodno »Kdo bo Tebe troštal « za violino in klavir.

Komponiranje pa pripelje skladatelja $\mathrm{v}$ njegovem zrelem, ljubljanskem obdobju, ko popolnoma suvereno oblikuje glasbene misli, tudi na mejo dodekafonije, ki pa je ne prekorači; in sicer v Sonati pour violoncelle et piano. Že leto poprej, v klavirski Fantasie chromatique, skladatelj na začetku II. stavka vplete kompletno dvanajsttonsko serijo, četudi jo potem ne uporablja kot izhodišče za nadaljnje oblikovanje, ampak samo kot napoved bolj ali manj svobodne obravnave poltonov kromatične lestvice. V Scherzandu prej omenjene Sonate pa gre nekoliko dalje, saj moremo serijo dvanajstih tonov, s katero stavek začne, imeti za nekakšno temo, ali vsaj za eno izmed tematičnih oporišč stavka. Kljub temu, da napoveduje podobno obravnavo 


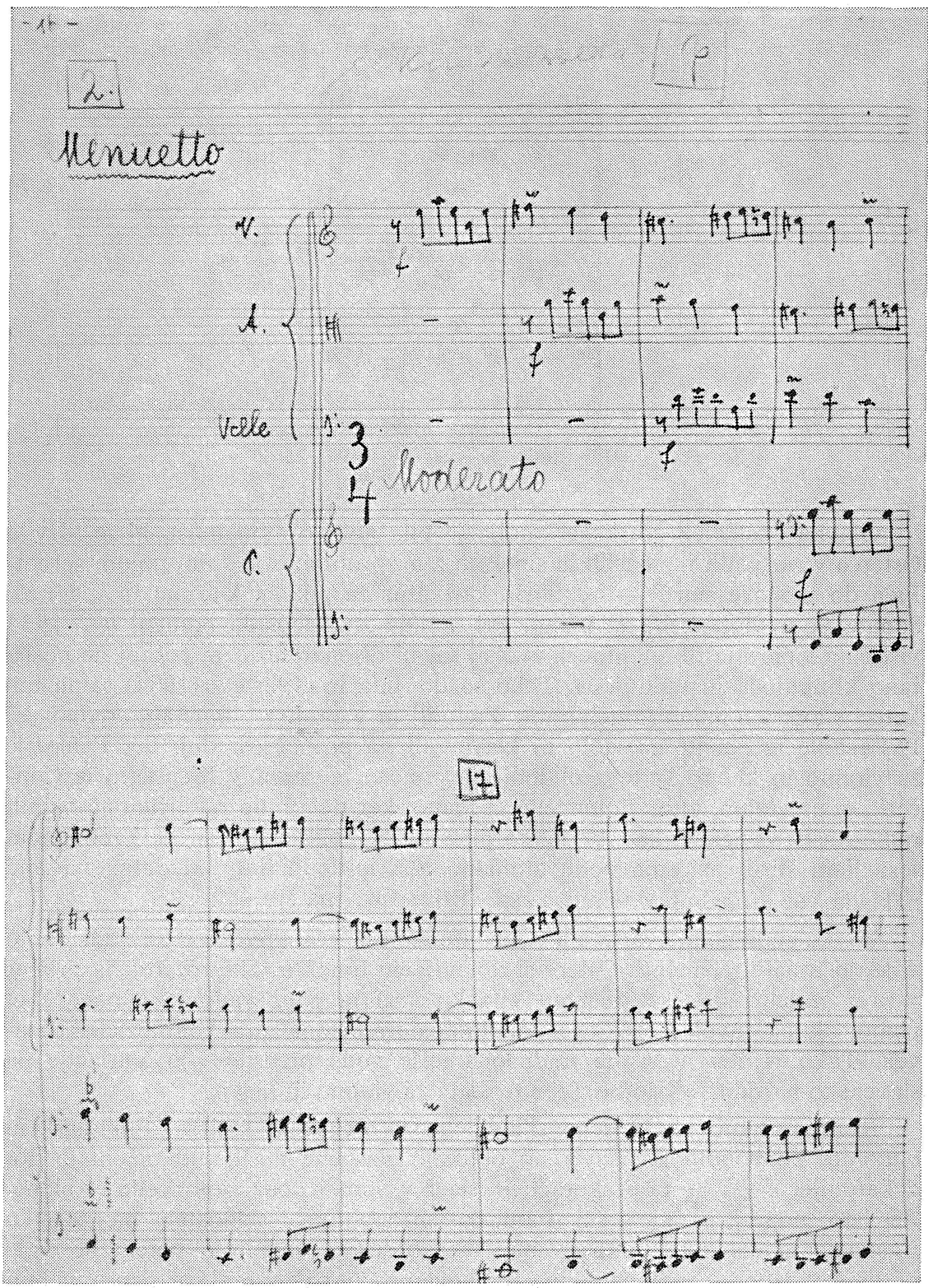


poltonov, kakor to nakazuje serija $\mathrm{v}$ Fantasie chromatique, pa to serijo $\mathrm{z}$ nekaterimi enharmonskimi zamenjavami - vsaj enkrat ponovi (takti 26 do 29), kar se pri Fantasie chromatique nikoli ne zgodi. Vendar je to tudi vse, saj v nadaljnjem razvoju stavka ne uporablja potencialnih gradbenih možnosti, ki so prisotni $\mathbf{v}$ dani seriji. Dokaz, da Osterc dvanajstih poltonov temperiranega sistema ni serialno urejeval in da so ti primeri samo rahli odmevi drugačnih gradbenih nazorov, ki se jim sam ni priključil, kažejo nadaljnji takti istega Scherzanda: takoj za omenjeno »temo « sledi nova serija dvanajstih tonov, ki s prejšnjo nima zveze, ki se sama, ne $\mathrm{v}$ celoti ne $\mathrm{v}$ posameznostih, nikoli ne ponovi in ki ob svobodnem kontrapunktu basovskega glase zapelje nazaj $\mathrm{v}$ atonalno tretiranje zvoka.

Če se sedaj omejimo na vertikalo $\mathrm{v}$ ožjem pomenu besede, se pravi na posamezna sozvočja, vodi njih analiza do spoznanja, da slone na različnih sistemih gradnje akordov, pri čemer so le-ti le redko »čisti«, ampak se medsebojno prekrivajo.

Osterc je izšel iz dur-molovskega sistema, pri katerem sloni oblikovanje sozvočij na terčni gradnji. V zgodnjih delih zato prednjačijo temu ustrezne harmonije - od navadnih trizvokov, in obrnitev, do alteriranih, in obrnjenih, non- in undecimakordov. Še celo v Allegru appassionatu in Passacaglii I. godalnega kvarteta je tako. Začetek prvega stavka je prav poučen, ker so stalno spreminjajoče se harmonije terčno razložljive. Nimajo pa funkcionalne zveze $\mathrm{z}$ osnovno linijo $\mathrm{v}$ violi, ampak nastajajo, deloma $\mathrm{z}$ zadržki, v pretežno sekundnem gibanju glasov. Da se bo zvok v nadaljnjem skladateljevem snovanju izostril, napove Fuga. Ne toliko v sami temi, ${ }^{9}$ ampak v prvem dvoglasju med kontrapunktom in njenim ponovnim nastopom. Poveča se namreč število disonantnih intervaloy, ki so glede svojega mesta na lahkih oziroma težkih dobah že izravnani s konsonancami. ${ }^{10}$ Še bolj seveda $\mathrm{v}$ nadaljnjih delih, ko na primer vzporedno mesto v Ouverture Concerta pour violon, alto, violoncelle et piano izpričuje $\mathrm{v}$ glavnem male in velike sekunde, septime in none ter zmanjšane in zvečane oktave. Ker pa je bilo že ugotovljeno, da se mnoge tradicionalne tonalne značilnosti vlečejo $\mathrm{v}$ skladateljevo ljubljansko razdobje, je nujno, da je tudi terčni način formiranja akordov občasno prisoten. Valse iz Suite za 8 instrumentov je $\mathrm{v}$ očitnem F-duru $\mathrm{z}$ neproblematičnimi terčnimi harmonijami. Ima pa kontrasten srednji del, kjer so na basov ton toni naloženi tako, da jih moremo imeti, če jih z upravičenimi obrati stisnemo $\mathrm{v}$ okvir čiste kvinte, za nedosledne sekundne tvorbe. (Glej notni primer na strani 46 zgoraj.) Pogled na prve štiri takte Chaconne iz Partite pour violoncelle et piano zopet kaže, kako Osterc vpleta kvartne harmonije v terčno fakturo, pa čeprav jih (in ravno zavoljo terčnega okolja jih) postavlja $\mathrm{v}$ intervalu čiste kvinte. ${ }^{11}$ Dober primer za terčne harmonije, ki si sledijo $\mathrm{v}$ počasnem, za Osterca tako značilnem »quasi choral « tempu in v tradicionalno se odvijajočem funkcionalnem sosledju, je odlomek iz Larghetta Suite za violino in klavir. Ne glede na dodane sekunde, ki polnijo vertikalo, ni osnovna har-

9 Gl. prvi notni primer.

10 Prim. Persichetti V., Twentieth Century Harmony, London 1961, 14.

11 Tako na 3. dobi 1. takta, 1. in 2. dobi 3. ter 1. dobi 4. takta. Prim. drugi notni primer, in Persichetti V., ib., 104. 


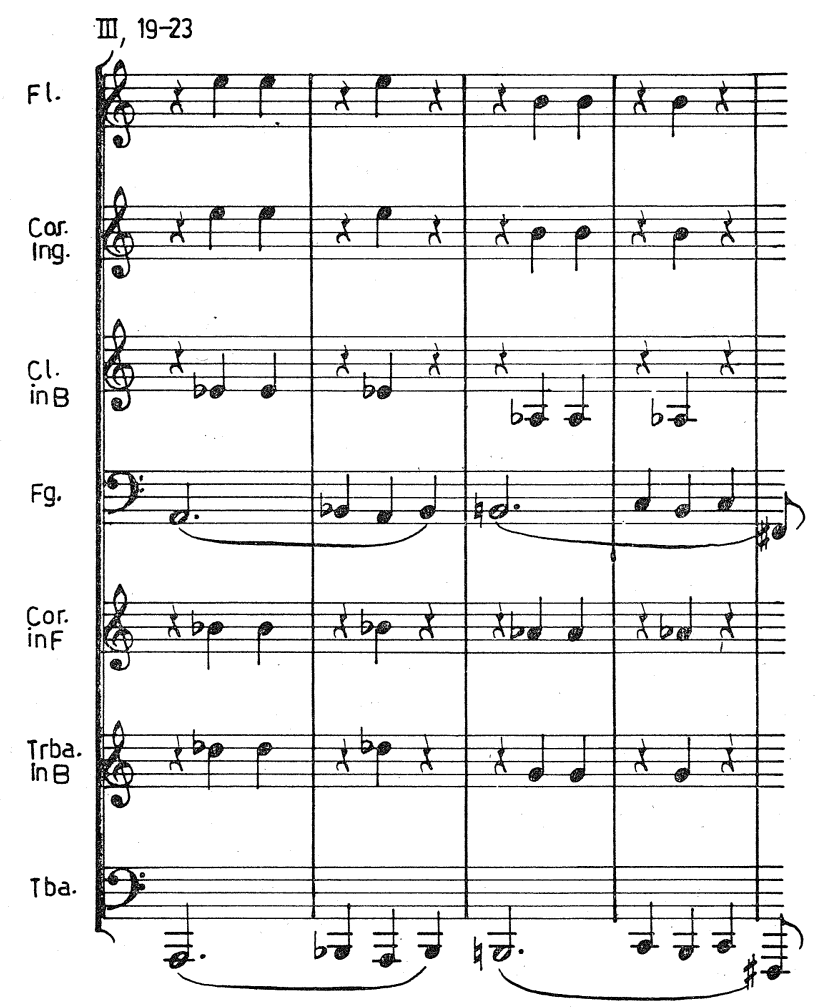

monska shema nikoli vprašljiva, pa čeprav pomembni toni niso vedno pripravljeni, niti se strogo ne razvezujejo. ${ }^{12}$ Glede na čas nastanka je terčno IV, 9-13

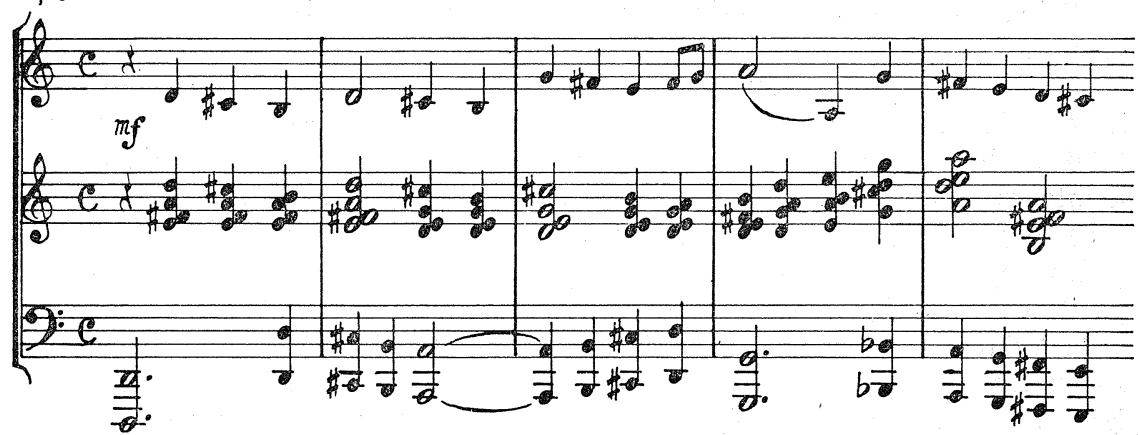

podobno presenetljiv začetek Kvinteta za pihala, saj si kljub dodanim sekundam akordi slede $v$ naslednjem, jasnem zapovrstju: Fis D $7-\mathrm{G}^{5}{ }_{3}$, E D 7

12 Glede na dominantni značaj polzaključka $\mathrm{v}$ 4.taktu predstavlja npr. basov ton septimo, ki na četrto dobo kot podlaga sekstakorda skoči na terco subdominantne harmonije. 
- $\mathrm{F}^{5} /_{3}$, Cis $\mathrm{D} 7-\mathrm{D}^{5} /_{3}, \mathrm{H} \mathrm{D} 7-\mathrm{C}^{5} /{ }_{3}$.Zanimivo pa je, kako zna Osterc $\mathrm{v}$ popolnoma atonalno fakturo vključiti harmonije, ki dovoljujejo tudi terčno razlago. V I. stavku Sonate za saksofon in klavir ima v klavirski spremljavi naložena dva podobna akorda. Naj ju, oziroma celotno vertikalo, slišimo

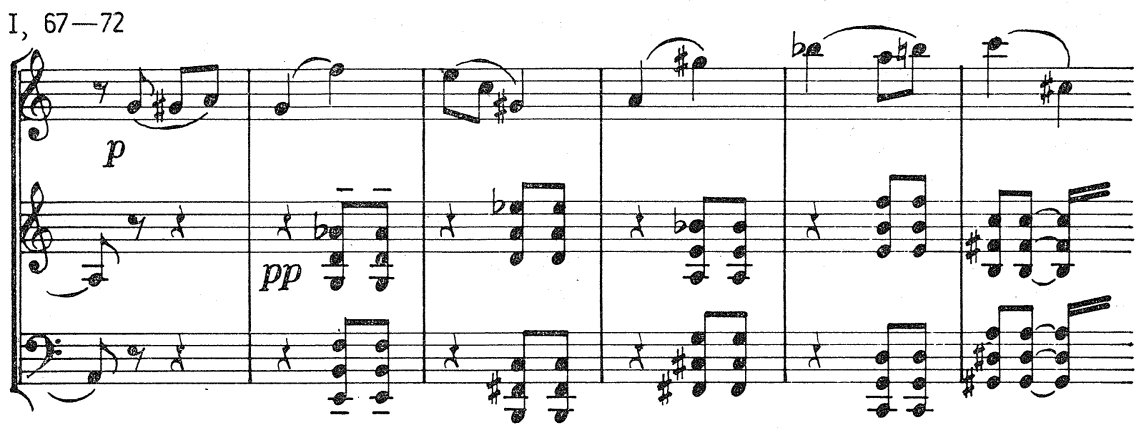

kvartno - kar je manj verjetno, ker kvintna struktura megli značilno kvartno zvočnost, ali terčno (kot teoretično možne undecimakorde), je še bolj značilno, kako je skladatelj zaostril vertikalo: $\mathrm{z}$ intervali velikih sekund oziroma non med vrhnjim tonom leve in najnižjim tonom desne roke, ter zlasti $\mathrm{z}$ intervalom še disonantnejše male none, ki tako $\mathrm{v}$ diskantu kot $\mathrm{v}$ basu klavirske spremljave oklepa obe sozvočji.

Tudi če uporablja vzporedno akordiko, tega ne dela zavoljo ustvarjanja kakšne impresionistične barvitosti, ampak zaradi kontrasta in razširitve zvočnosti v smeri funkcionalne nedoločljivosti. Kar torej zadeva terčne harmonije, je razumljivo, da so ustrezni primeri - od durovih in zvečanih trizvokov do nepopolnih undecimakordov - iz njegovih zgodnejših del. ${ }^{13}$

Kvartne harmonije prinese študij $\mathrm{v}$ Pragi ${ }^{14}$ in te spremljajo skladatelja do njegovih zadnjih atonalnih stvaritev. ${ }^{15} \mathrm{~V}$ tej zvezi je tipičen zlasti začetek

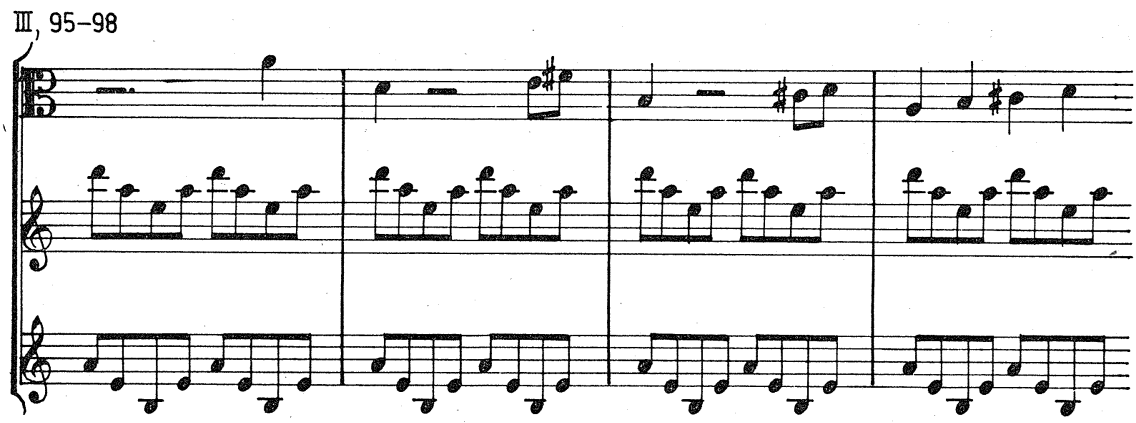

13 Prim. npr. Godalni kvartet v a-molu, 60; Divertimento za kvartet na lok, II, 3; I. godalni kvartet, I, 132, 150 sl.

14 I. godalni kvartet, I, 143 sl.

15 Prim. Sonate pour violoncelle et piano, I, $30 \mathrm{sl}$. 
zaključnega dela Fuge Sonate za violo in klavir, saj sloni na razloženem kvartnem sozvočju. V njem najbolj izstopa ton d, ki je ne samo osrednji ton celotnega stavka, ampak na tem mestu tudi durovska tonika začetnih motivov teme.

Tipična značilnost Osterčeve glasbe so seveda akordi, pri katerih so osnovnim akordnim tonom pridodane sekunde. Le-te ne predstavljajo kakih okrasnih tonov, ampak bistveno prispevajo svoj delež $\mathrm{k}$ barvi in nasičenosti vertikale. Oboje je odvisno od njihovega mesta in lege v sozvočju. ${ }^{16}$ Klasičen primer tovrstne skladateljeve fakture je tema iz Variacij na slovensko narodno »Kdo bo Tebe troštal«.

Nekaj popolnoma drugega so sekundne harmonije, ki so podobno kot prejšnje, do študija $v$ Pragi, izjemne. Sem ne bi smeli šteti mesta iz II. stavka Divertimenta za kvartet na lok, saj ima sekundno sozvočje spremljevalnih

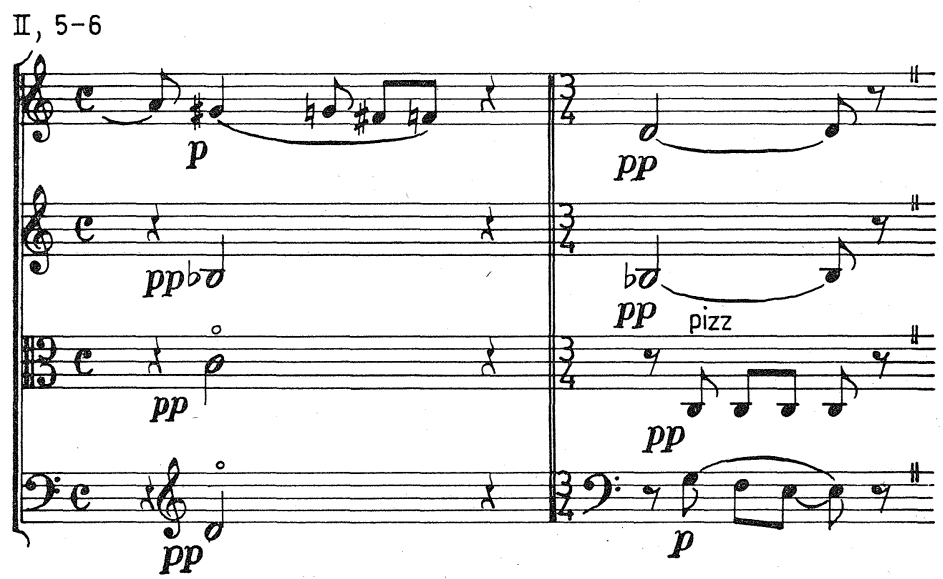

instrumentov glede na harmonijo naslednjega takta pravzaprav značaj nepopolnega dominantnega nonakorda. Pa četudi bi šlo za utrinek sekundnega sozvočja, je stavek $\mathrm{v}$ tako trdnem objemu F-dura, disonantnost omenjenega akorda pa tako blaga, da ga nikakor ni moč čutiti ko tujerodno primes $\mathrm{v}$ okviru osnovne tonalitete. Pravi začetki takega harmonskega mišljenja so šele $\mathrm{v}$ zavestnem sekundnem grajenju vertikale. Najprej samo v diafoniji dveh instrumentalnih glasov. ${ }^{17}$ Ta in taka sekunda sozvočja z leti vse bolj brstijo, ${ }^{18}$ nikoli pa v komornem instrumentalnem opusu ne dosežejo stopnje clusterjev, kot jih izpričujejo nekatere sočasne skladateljeve klavirske skladbe. Kljub temu so sekundne tvorbe značilna sestavina Osterčevega kompozicijskega stavka; tudi v zadnjem delu, Sonati pour violoncelle et piano:

16 Persichetti V., ib., 111 sl.

17 Gl. npr. Silhuete, I, 5.

18 Prim. II. godalni kvartet, I, 4-5, ali zaključek Allegra v Kvintetu za pihala. 


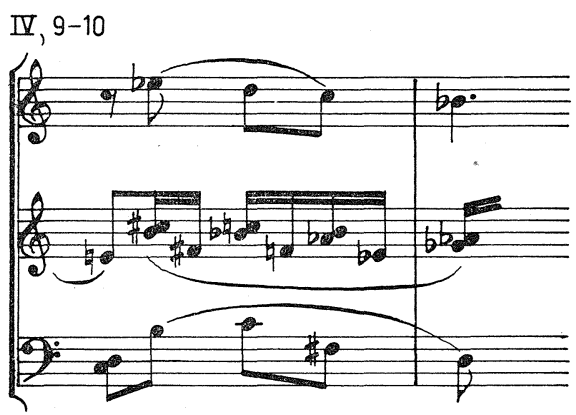

Zložene harmonije so $\mathrm{v}$ bistvu zvočne mase, ki predstavljajo simultano vertikalno kombinacijo različnih intervalov. ${ }^{19}$ Kratek izsek iz Noneta to od-

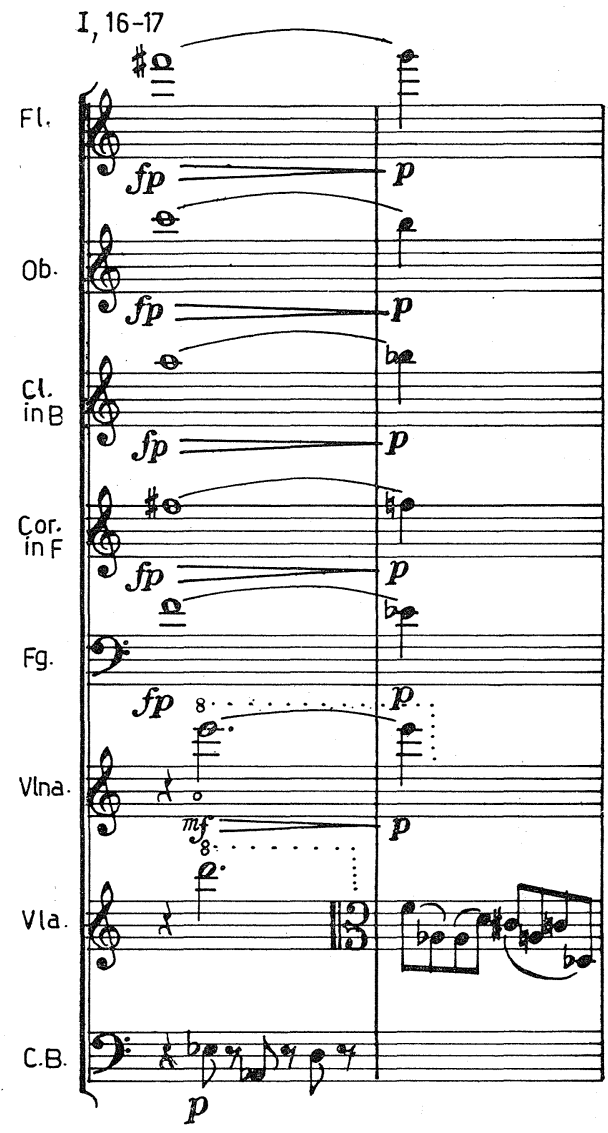

19 Prim. Persichetti V., ib., 163 sl. 
lično ponazori. Pihala skupaj z rogom zastavijo najprej polikordno sozvočje, ki ima zgoraj kvartno, spodaj pa terčno razložljive korenine. Že na drugo dobo pa godala $\mathrm{z}$ dodatnimi toni zaostrijo napetost, ki se $\mathrm{v}$ skoraj izključno malih sekundnih postopih posameznih instrumentov nekoliko zmanjša $\mathrm{v}$ naslednjem taktu. Slednji akord ima namreč $v$ primerjavi $s$ prejšnjim manj disonantnih intervalov, $s$ čimer se zmanjša napon na tem mestu izrazito navpično tretirane zvočnosti.

V praksi se vertikalni princip ne samo izmenjuje, ampak tudi prepleta z horizontalnim. Čeprav je horizontalno mišljenje Ostercu gotovo važnejše od vertikalnega, pa to ne pomeni, da je zvočnost, ki tako nastaja, slučajna. Ker, če je Osterc na primer vpel polifonijo godalnega kvarteta iz leta 1923 $\mathrm{v}$ »a-mol«, pomeni to, da je tako hotel in da je tako tudi slišal. Če pa je pod vplivom študija na praškem konservatoriju deloma izravnal tradicionalne konsonance in disonance tako $\mathrm{v}$ horizontali kot $\mathrm{v}$ vertikali, je to gotovo storil zavestno. In če $\mathrm{v}$ taki instrumentalni polifoniji nastajajo sozvočja, ki jih ni možno dosledno kategorizirati $\mathrm{z}$ nobeno enovrstno intervalno analizo, je to samo teoretična posledica Osterčevega zavestnega hotenja pri oblikovanju zvoka. Iskal je pač nove, še neizrabljene zvočne možnosti in zato vodil instrumentalne glasove tako, da so mu v vertikali rezultirali, kakor je želel in kakor to izpričuje notna podoba njegovih partitur.

Če se na primer že 15. in deloma 16. takt Godalnega kvarteta v a-molu obravnava samo s terčno ali kakšno drugo intervalno analizo, se pride do zaključka, da taka pot ne pelje daleč. ${ }^{20}$ Napak pa bi bilo sedaj trditi, da so ta in taka sozvočja »napačna«, ker jim s tradicionalnimi sredstvi ne moremo do živega in ker jih ne moremo vtakniti $\mathrm{v}$ funkcionalno harmonijo. Taki pasusi so sicer $\mathrm{v}$ tem času še izjemni, a s svoje strani nakazujejo posamezne značilnosti »klasičnega« Osterca. Z obravnavanega vidika le-ta plastično izstopa v Fughetti iz Štirih karikatur za pikolo, klarinet in fagot. Naslednji primer predstavlja začetek vstopa fagota, katerega glavo teme spremlja kontrasubjekt v pikolu in svobodni kontrapunkt v klarinetu (in B). Celotni stavek

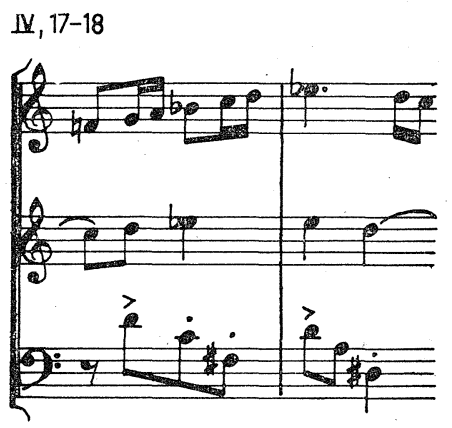

je motorično razgiban, $\mathrm{z}$ intervalno značilnimi in močno diferenciranimi instrumentalnimi linijami, katerih razvoj in preplet pomenita bistvo zastavljene

${ }^{20}$ Gl. Rijavec A., ib., 94--95. 
forme. V kakšnem zvočnem svetu se gibljejo, oziroma še bolje, kakšen je vsakokratni harmonski rezultat tako oblikovanega zvoka, pokaže zasledovanje sozvočij v omenjenih taktih. Seveda se kaže poslužiti vseh gradbenih principov, ki se uporabljajo v harmoniji 20. stoletja ne glede na to, da bo rezultat pokazal, da se medsebojno izmenjujejo. Prvi takt: čista kvarta; druga obrnitev kvartnega akorda, ki se »razveže $\mathrm{v}$ durov trizvok in tako »tonalno « podpre začetni ton atonalno oblikovane teme; na začetku druge dobe je nepopolni nonakord; nato dve sozvočji, ki imata obakrat disonantno malo sekundo $\mathrm{v}$ diskantu. Drugi takt: disonanca je še večja, ker intervala zmanjšane oktave in male sekunde oklepa mala nona; zavoljo »blažjih « intervalov napetost $\mathrm{v}$ naslednjih dveh akordih, zlasti na drugo dobo (enharmonija!) močno vsahne, da bi se na predzadnji osminki (zmanjšana septima in mala sekunda, ki jo oklepa zmanjšana oktava) ponovno zaostrila; zadnja vertikala predstavlja mehko konsonanco, saj zmanjšana septima slušno ustreza veliki sekti. Če povzamemo, je zanimivo, da od devetih sozvočij (dvakrat tvorita vertikalo itak samo intervala) vsebuje kar pet harmonij po eno disonantno veliko ali malo sekundo, da ostalih, večjih disonanc niti ne omenimo. Če pa se $\mathrm{k}$ temu še prišteje vodoravno gibanje glasov, ponovno vzbudi pozornost dejstvo, da se glasovi na eni strani gibljejo predvsem $\mathrm{v}$ sekundnih postopih, na drugi pa $\mathrm{v}$ kvartah, nemirnih tritonusih, $\mathrm{v}$ razponu zmanjšane oktave oziroma velike septime in podobno. $\mathrm{S}$ tem pa so podane vse glavne koordinate, ki karakterizirajo zvočno podobo citirane kompozicije, ki je obenem tipična za Osterčev kompozicijski stavek.

Pri določanju odnosa vertikale do horizontale se ponuja še en vidik, ki značilno osvetljuje skladateljevo povezanost $\mathrm{z}$ nekaterimi podedovanimi principi oblikovanja zvoka. Gre za vprašanje vstopanja instrumentalnih glasov v zvočno tkivo. Pokazalo se je namreč, da tudi ta element karakterizira kompozicijski stavek in da bistveno določa deloma dokončne deloma pa vsaj začetne vertikalne odnose med posameznimi, polifonsko nastopajočimi glasovi. Vse do začetka izrazitejše atonalne faze (1934) sledi reperkusija tradicionalnemu tonalnemu planu: T-D-T ali T-D-T-D, kar je pač odvisno od števila glasov. Vendar pa ima ta tonalni plan določene posledice. Kakšne so njegove posledice v dur-molovskem sistemu, je znano. Značilno pa je, da veže Osterc tako reperkusijo tudi na stavke, pri katerih je možno govoriti samo o njih osrednjem tonu, kar prispeva $\mathrm{k}$ njihovi utrditvi ter $\mathrm{k}$ nagibanju $\mathrm{k}$ določeni tonaliteti. To lepo kaže ekspozicija Fuge iz Concerta pour violon, alto, violoncelle et piano. Citirano reperkusijo pa je zaslediti tudi $\mathrm{v}$ atonalnih stavkih; na primer $v$ Fughetti $v$ Štirih karikaturah. Če $v$ prejšnjem primeru »toničnodominantna reperkusija prispeva celo $\mathrm{k}$ nagibu $\mathrm{v} \mathrm{D}$-dur, pa je njen vpliv $\mathrm{v}$ atonalni fakturi manjši, saj samo nekoliko pomaga pri poudarjanju začetnega tona teme. $S$ tem se seveda ruši tako imenovana čistost kompozicijske zasnove, kar je Ostercu vedno zelo pri srcu. V obeh teh in mnogih drugih primerih je reperkusija vedno realna ${ }^{21}$ in samo v Fugi Sonate za violo in klavir tonalna, $\mathrm{s}$ čimer so funkcionalne posledice $\mathrm{v}$ smislu tonalnih odnosov še večje.

${ }^{21}$ Prim. še: I. godalni kvartet, III; Koncert za violino in 7 instrumentov; Suita za 8 instrumentov, V; Partita za violončelo in klavir, IV. 
Oktavni vertikalni odnosi med vstopajočimi glasovi izključujejo dominantno sestavino in samo pomagajo do izstopanja bodi središčnemu tonu ${ }^{22}$ bodi toniki, katere funkcija je tudi sicer določena $\mathrm{z}$ ustreznimi harmonijami. ${ }^{23}$ Dosledne kvinte nimajo nikakršnih tonalnih vplivov. Celo narobe: od samega začetka razbijajo vsak morebitni pomislek o tonalnosti stavka; še zlasti, ker Osterc uporablja obravnavano reperkusijo v kanonih, in sicer tako, da že prva risposta vstopi nasproti proposti $\mathrm{v}$ odnosu zmanjšane oktave oziroma zvečane prime. Na ta način sta oblikovana Kanon v Silhuetah in Menuetto v Concertu. Če v prvem primeru veže skladatelj atonalno $s$ tonalnim in zaokroži stavek $v$ F-duru, pa $\mathrm{v}$ drugem ostane zvest izhodiščnemu, kvintnemu vertikalnemu odnosu med instrumentalnimi glasovi. ${ }^{24}$

Zaostrevanje fakture, ki se začne s praškim študijem, najde svoj odmev tudi v citiranem vprašanju. Najprej samo v posameznih razvojnih delih polifonskega tkiva, kot na primer na začetku izpeljave I. stavka (Ouverture) Concerta, ko vstopajo glasovi $\mathrm{v}$ intervalih velike sekunde oziroma male none. Po letu 1934 pa prodrejo taki vertikalni odnosi tudi v ekspozicije polifonsko zastavljenih stavkov. Eksemplarično to kaže začetek zaključnega Allegra iz Sonate pour violoncelle et piano. Instrumentalni parti začenjajo $v$ vertikalnih presledkih dvakrat zvečane kvarte in zvečane oktave, kar je nedvomno značilna postavka pri odkrivanju skladateljevega oblikovanja zvoka, oziroma, v
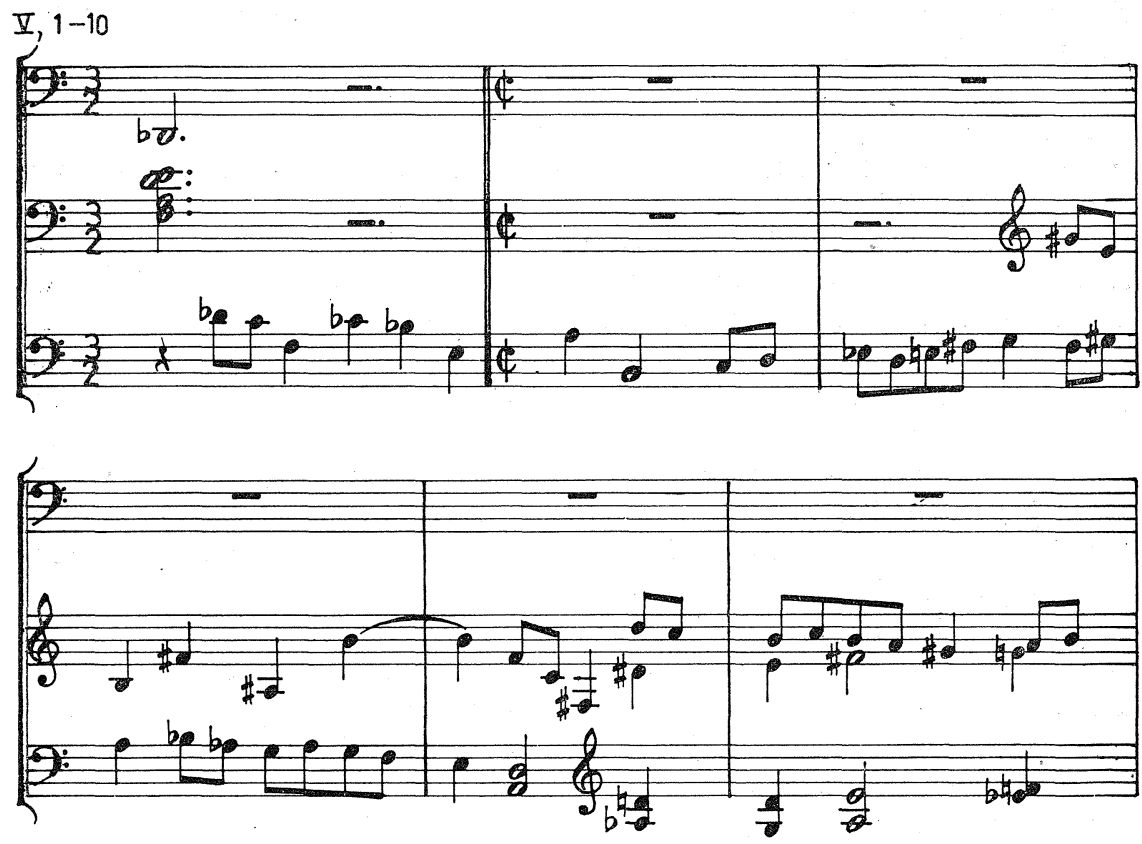

22 G1. npr. Concerto pour violon, alto, violoncelle et piano, I, ali oba B dela Fantazije za violino in klavir.

${ }_{23}$ Prim. Concerto pour violon, alto, violoncelle et piano, III.

24 Prim. faksimile na str. 44. 


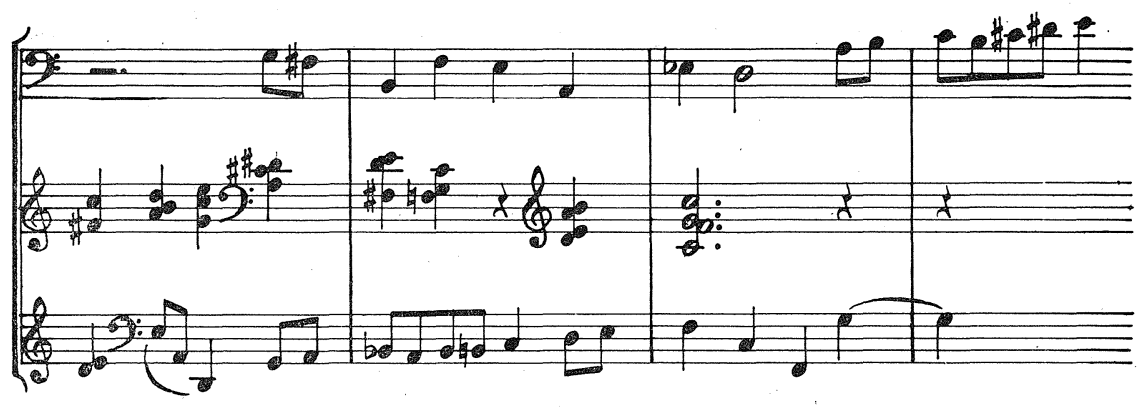

smislu naslova tega sestavka - razreševanju vprašanja tonalnosti in vertikale v njegovih skladbah.

\section{SUMMARY}

In the analysis of Classical music and partly of Baroque and Romantic music as well - in all the latter's late and belated forms - the harmonics, that is to say the traditional theory of the functional progressions of chords, are a helpful basis for the explanation of harmonies. Functional harmony is, however, only one of the principles of Osterc's compositional technique. Therefore only some passages of his music can be explained through this, and therefore, naturally, there are only a few compositions which can be placed within traditional tonality. There are more, in which one can speak of a tonal centre. After his studies in Prague atonality comes to the fore but not always consistently, because Osterc combines it with tonal principles as well as with series which are never exploited dodecaphonically. The combining of different principles is characteristic of Osterc on the whole, i. e. the combination of traditional with new, new with traditional, a synthesis of the expected and unexpected.

The analysis of individual harmonies reveals a whole kaleidoscope of chords, typical of much of the music of the first half of the 20th century: more or less complete chords by thirds - from triads to thirteenths, by fourths, added-note chords, chords by seconds, polychords and compound harmonies.

As, in practice, vertical principles not only interchange with horizontal ones but are also interwoven with them, some aspects of these relations are dealt with in the article; especially considering the fact that for Osterc horizontal thinking is more important and therefore more typical. This does not mean, of course, that the sonority which thus results is accidental. The analysis of some passages of his music shows that his instrumental lines are consciously formed into harmonies he heard in his search for new, as yet unexploited sounds. 